\title{
HYDATID CYST IN THE SOFT PALATE: A RARE CASE REPORT
}

\section{Raghunatha Babu Gudupudi, Parasuram Gudepu², Muralidhara Rao Seepana3,} Ramesh Chandra Paidi' ${ }^{4}$ Aditya Kanchumurthy ${ }^{5}$

\section{HOW TO CITE THIS ARTICLE:}

Raghunatha Babu Gudupudi, Parasuram Gudepu, Muralidhara Rao Seepana, Ramesh Chandra Paidi, Aditya Kanchumurthy. "Hydatid CYST in the Soft Palate: A Rare Case Report". Journal of Evolution of Medical and Dental Sciences 2015; Vol. 4, Issue 25, March 26; Page: 4371-4374, DOI: 10.14260/jemds/2015/630

ABSTRACT: Hydatid disease is caused by tapeworm that occurs primarily in sheep, while dog is the definitive host. It is most frequently caused by Echinococcus granulosus. It mostly affects liver and lungs. Hydatid cyst can be localized in different organs such as bone, brain, heart, gall bladder, pancreas, infra temporal fossa, nasopharynx etc. Presentation in head and neck is a rare entity. This case report emphasizes that hydatid cyst can be included in differential diagnosis of palatine mass.

KEYWORDS: Palate, Hydatid cyst, Hydatid disease, Head and neck.

INTRODUCTION: Hydatid disease is endemic in Middle East Africa, South America, New Zealand, Australia, Turkey and southern Europe, but foci are common in almost every part of the world including India, where the highest prevalence is reported in Andhra Pradesh, Tamilnadu and Jammu and Kashmir.[1]

Hydatid cyst can occur in any organ of the body. Presentation is more common in liver (55\%$70 \%$ ) followed by lung (18\%-35\%). Incidence of unusual sites is about $8 \%-10 \%$. Incidence of hydatid disease involving the spleen, kidney, peritoneal cavity, skin and muscles is about $2 \%$ each. Incidence of heart, brain, vertebral column, ovaries, pancreas, gallbladder, thyroid gland, breast and bones is about 1\% each. ${ }^{[2]}$ Involvement of head and neck region by hydatid cyst is very rare and only few cases have been reported till date in literature.[3] Multiple hydatid cysts of the neck, the nasopharynx and the skull base revealing cervical vertebral hydatid disease. ${ }^{[4]}$ as well as hydatid cyst in infratemporal region ${ }^{[5]}$ have been reported.

CASE REPORT: A 60 yrs female presented with swelling in the palate for 3 months to the Government ENT Hospital, Visakhapatnam, which was insidious in onset, slowly progressive and not associated with fever or any history of trauma. Patient's personal history revealed close proximity to dogs and cattle.

On clinical examination a sub mucosal firm swelling of size $3 \mathrm{~cm} \times 2 \mathrm{~cm}$ which was non-tender was identified (Fig. 1). No local rise of temperature was seen.

Blood investigations revealed slight rise in eosinophillic count. Fine needle aspiration cytology (FNAC) revealed the presence of cystic fluid which on magnification showed hooklets and the protoscolices of the hydatid disease (Fig. 2).

In Magnetic Resonance Imaging (MRI) a cystic mass of size $4 \mathrm{~cm} \times 3 \mathrm{~cm} \times 1 \mathrm{~cm}$ identified in the palate, which exhibiting low signal in T1 weighted images (Fig. 3) and high signal in T2 weighted images (Fig. 4). The cystic lesion was round and well delineated. Inner germinal layer is identified in the cyst.

Ultrasound abdomen and chest x-ray were normal. 
Intra operatively there is a $4 \mathrm{~cm} \times 3 \mathrm{~cm} \times 1 \mathrm{~cm}$ cyst in the soft palate. The cyst was removed en masse by an incision over the hard palate by elevating in sub mucoperiosteal plane (Fig. 5). Patient was kept on Albendazole 400 mgs twice daily for one month.

Histopathological examination demonstrated a germinal layer, lamellated ecto cyst with fibrous outer layer (Fig. 6). Marked foreign body type giant cell reaction was also seen confirming hydatid cyst.

DISCUSSION: Causative agent of hydatid disease is Echinococcus granulosus also called as dog tape worm. Dog is the definitive host, sheep is an intermediate host whereas man is an accidental host. Humans are affected by the contamination of food by the eggs found in faeces excreted by the infected animals. After the development of the embryo, various organs were infested by its migration through intestinal mucosa.[6] It can develop in any organ of the body. Presentation in palate is a very rare entity.

Patients with Echinococcus infestation must undergo thorough systemic investigations because $20 \%$ - 30\% have multi organ involvement. Hydatid cyst in palate in the absence of disease in lung and liver may be due to systemic dissemination through lymphatic root, is a strong possibility in case of unusual presentation sites.[7]

The diagnosis of Echinococcus infection mainly depends on the clinical history of the patient, diagnostic radiological findings and serological tests. ELISA (Enzyme linked Immuno Sorbent Assay), Casoni skin test, latex agglutination, immune electrophoresis, and direct hemagglutination are serological methods used for the diagnosis of hydatid disease. An increase in titre indicates recurrence of disease and decrease in titre indicates resolution.[8][9]

Definitive treatment for hydatid cyst is surgical excision followed by chemotherapy to avoid recurrence.[1] Per oral aspiration is not done to avoid systemic dissemination and acute anaphylactic reaction.

The diagnosis of hydatid cyst is confirmed by histology.[3] Our case demonstrates histopathologically protoscolices, an acellular, thick, lamellar cyst wall. The surrounding host reaction, which is composed of the inflammatory fibrous tissue forming a dense pseudo-capsule around the cyst, confirms the diagnosis of hydatid cyst.

CONCLUSION: Hydatid cyst should be kept as differential diagnosis of palatine mass especially in regions where Echinococcus infestation is endemic. FNAC is a good tool for the diagnosis, but risk of anaphylaxis is a major concern.

Hydatid cyst in palate as primary hydatid disease without secondary cysts in other organs of the body is a rare entity and has not been reported to date.

\section{REFERENCES:}

1. Sachar S, Goyal S, Goyal S, Sangwan S; Uncommon locations and presentations of hydatid cyst. Annals of Medical and Health Sciences Reaserch May - Jun 2014, Vol. 4 Issue 3: 447 - 452.

2. McManus DP, Zhang W, Li J, Bartley PB. Echinococcosis. Lancet 2003; 362: 1295-304.

3. Katilmis H, Ozturkcan S, Ozdemir I, Adadan Guvenc I, Ozturan S; Primary hydatid cyst of the neck. Am J Otolaryngol 2007, 28: 205-207. 


\section{CASE REPORT}

4. Asma El Kohen, Abdelaziz Benjelloun, Abdeljalil El Quessar, Said Derraz, Abdenasser Lazrak, Nezha Jazouli, Mohamed Kzadri; Multiple hydatid cysts of the neck, the nasopharynx and the skull base revealing cervical vertebral hydatid disease. International journal of pediatric Otorhinolaryngology 2003, 67: 655 - 662 .

5. K. Umesh, N. Sulabha A, C. Sameer A, W. Neelakant. M, N. C. Sangamesh and Patel Mohammad Ali R; Hydatid cyst of infra temporal region - A Rare Case Report. Al Ameen J Med Sci (2010)3 (1): 94 - 98. ISSN $0974-1143$.

6. Seema Khanna, Shashi Prakash Mishra, Dayanand Gupta, Satendra Kumar, A K Khanna and S K Gupta; Unusual presentation of hydatid cyst: a case report. International Journal of Research in Applied, Natural and Social Sciences (IJRANSS) June 2013, Vol. 1, Issue 1: 25 - 28.

7. Akal M, Kera M. Primary Hydatid cyst of posterior cervical triangle. J Laryngol Otol 2002; 116: $153-155$.

8. Aletras H, Symbas N: Hydatid disease of lung. In General Thoracic surgery. $5^{\text {th }}$ edition. Edited by Shields TW, LoCicero J, Ponn RB. Philadelphia: Lippincott Williams and Wilkins; 2000: 1113 1122.

9. Guney 0, Ozturk K, Kocaogullar Y, Eser 0, Acar 0; Submandibular and intracranial hydatid cyst in an adolescent. Laryngoscope 2002, 112: 1857 - 1860.

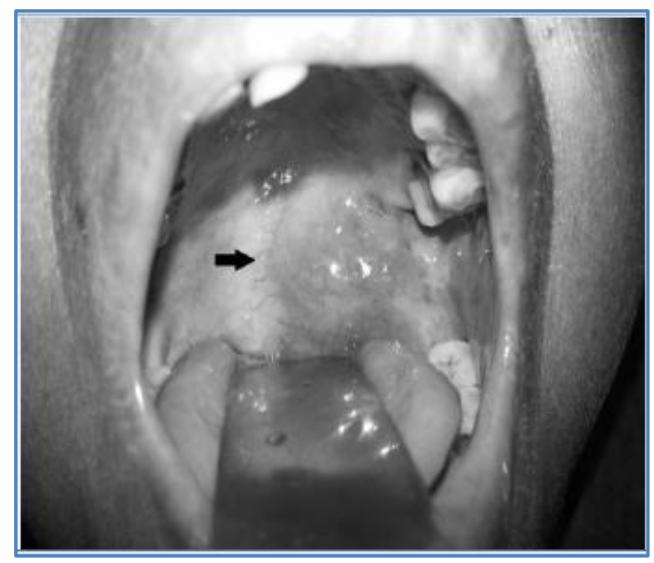

\section{Fig. 1: Clinical Pic}

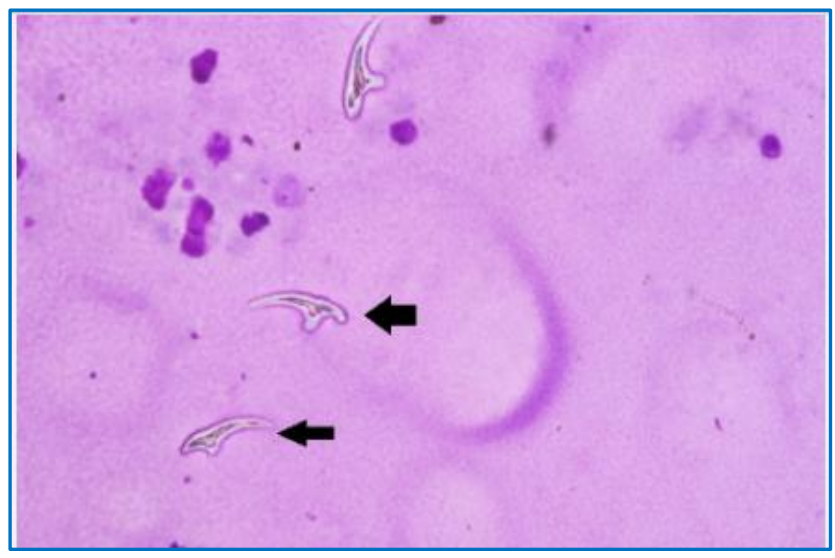

Fig. 2: FNAC 


\section{CASE REPORT}

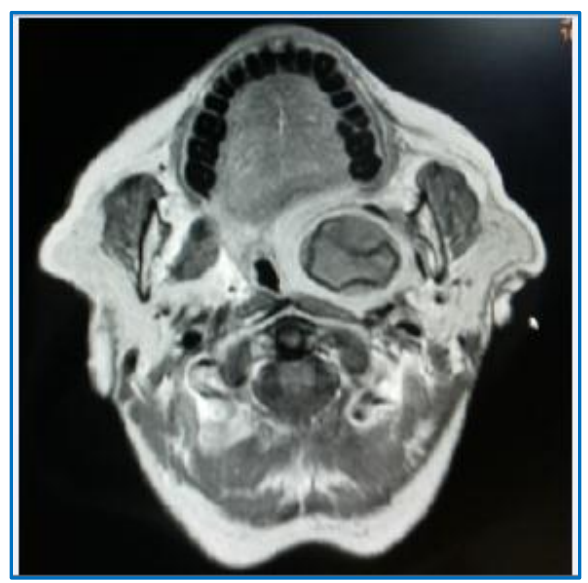

Fig. 3: MRI T1WI

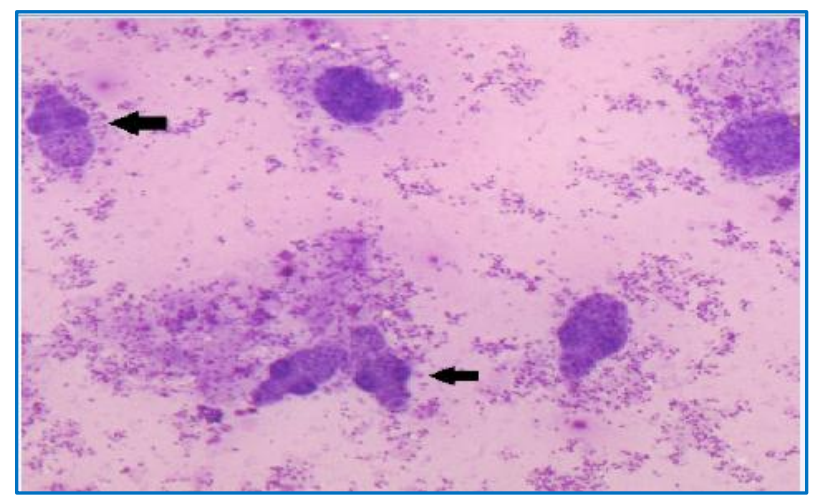

Fig. 5: Post OP HP

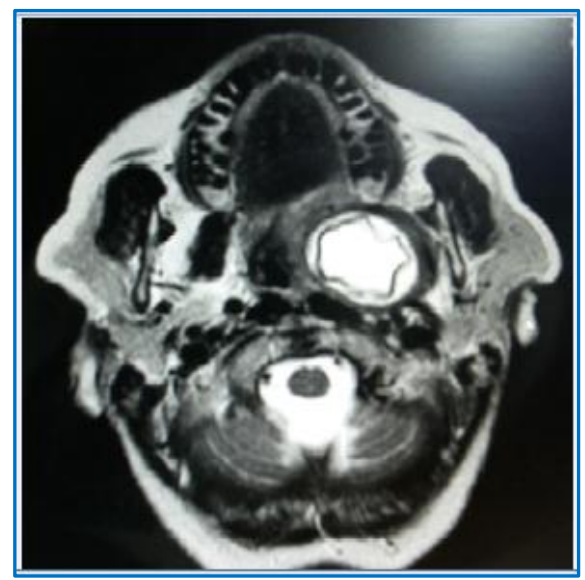

Fig. 4: MRI T2WI

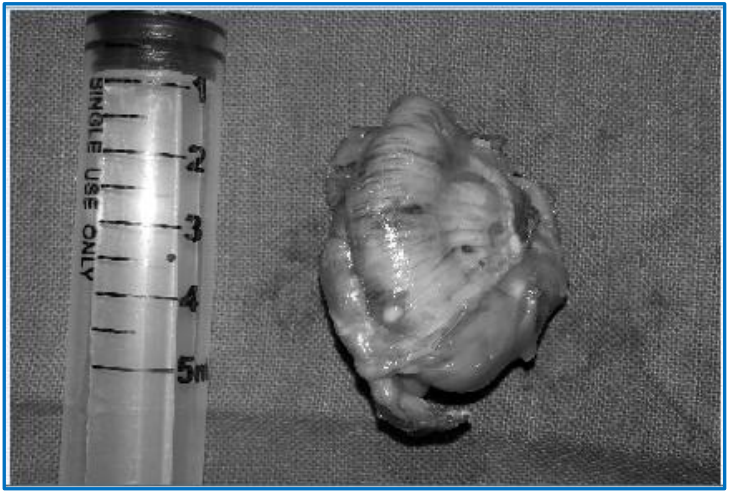

Fig. 6: Post OP Specimen

\section{AUTHORS:}

1. Raghunath Babu Gudupudi

2. Parasuram Gudepu

3. Muralidhara Rao Seepana

4. Ramesh Chandra Paidi

5. Aditya Kanchumurthy

\section{PARTICULARS OF CONTRIBUTORS:}

1. Professor, Department of ENT, Andhra Medical College.

2. Associate Professor, Department of ENT, Andhra Medical College.

3. Assistant Professor, Department of ENT, Andhra Medical College.

FINANCIAL OR OTHER

COMPETING INTERESTS: None

4. Assistant Professor, Department of ENT, Andhra Medical College.

5. Resident, Department of ENT, Andhra Medical College.

\section{NAME ADDRESS EMAIL ID OF THE CORRESPONDING AUTHOR:}

Dr. Aditya Kanchumurthy,

Flat No. 301, Swethavahana Residency, MIG 28, MVP Sector 1,

Visakhapatnam-530017.

E-mail: aditya.kanchumurthy@gmail.com

Date of Submission: 01/03/2015.

Date of Peer Review: 02/03/2015.

Date of Acceptance: 14/03/2015.

Date of Publishing: 26/03/2015. 